\title{
POLÍTICAS PÚBLICAS E DIREITOS HUMANOS POR IDOSOS EM SERVIÇO DE CONVIVÊNCIA
}

\section{PUBLIC POLICIES AND HUMAN RIGHTS FOR SENIORS IN LIVING TOGETHER CARE SERVICES POLÍTICAS PÚBLICAS Y DERECHOS HUMANOS POR ADULTOS MAYORES EN SERVICIOS DE CONVIVENCIA}

\author{
Fátima Fernandes Catão* \\ Kátia Karolina Rodrigues Rocha*
}

\begin{abstract}
RESUMO
No contexto de desigualdade no cotidiano brasileiro, tem-se por objetivo neste estudo refletir sobre os significados dos direitos humanos e políticas públicas, elaborados por idosos que vivenciam essa realidade. Participaram deste estudo 31 idosos, entre 65 a 89 anos de idade, em atendimento nos Serviços de Convivência e Fortalecimento de Vínculos para Idosos (SCFVI). Foram aplicados questionários sociodemográficos e entrevistas semiestruturadas. Utilizou-se da análise de conteúdo temática à luz do referencial da Psicologia sócio-histórica. Os significados de direitos humanos e políticas públicas configuraram-se entre "A responsabilidade é do governo e dos representantes", com 34,3\% das falas; "Ausência de direitos que alcancem a todos", com 31,9\%; e "Conhecimento/desconhecimento de políticas públicas", com 33,8\%. Concluiu-se que os idosos elaboram significados objetivados na necessidade de um olhar mais implicado da sociedade e das instituições para com o idoso, a humanização do vivido e o empoderamento na velhice.
\end{abstract}

Palavras-chave: Idosos. Direitos humanos. Políticas públicas. Desigualdade psicossocial. Psicologia sócio-histórica.

\section{ABSTRACT}

In the context of inequality in daily life in Brazil, this study aims to think over the meanings of human rights and public policies, elaborated by elderly people who go through this reality. This study included 31 people aged between 65 and 89 years old, who are under care at the Serviços de Convivência e Fortalecimento de Vinculos para Idosos (SCFVI) - Services for Living Together and Bond Strengthening for Elderly People. Sociodemographic questionnaires and semistructured interviews were applied. Thematic content was used in the light of the framework of sociohistorical Psychology.

\footnotetext{
"Professora Associada Universidade Federal da Paraíba (UFPB), NEIDH (Núcleo de Estudos Psicossociais da Exclusão/Inclusão e Direitos Humanos).E-mail: fathimacatao@uol.com.br.

** Psicóloga graduada pela UFPB, NEIDH. E-mail: kkarol.ina@hotmail.com.
} 
The meanings of human rights and public policies are pictured among "The responsibility lies with the government and the governors", with 34.3\% of the speech; "The absence of rights that reach everyone", with 31.9\%; and "Knowledge/ignorance of public policies", with 33.8\%. It was concluded that the elderly elaborated meanings aimed at the need for a more implicated look of the society and institutions towards the elderly, the humanization of living and the empowerment in old age.

Keywords: Elderly. Human rights. Public policies. Psychosocial inequality. Social-historic Psychology.

\section{RESUMEN}

En el contexto de desigualdad en la vida cotidiana vivida en Brasil, se tiene como objetivo, en este estudio, reflexionar sobre los significados de los derechos humanos y políticas públicas elaborados por adultos mayores que viven esta realidad. Participaron de este estudio 31 mayores entre 65 y 89 años de edad, en atendimiento en los Servicios de Convivencia y Fortalecimiento de Vínculos para Mayores (SCFVI). Fueron aplicados cuestionarios sociodemográficos y entrevistas semiestructuradas. Se utilizó un análisis de contenido temático a la luz del referencial de la Psicología sociohistórica. Los significados de los derechos humanos y políticas públicas se configuraron entre "La responsabilidad es del gobierno y de los gobernantes", con un 34,3\% de las hablas; "Ausencia de derechos que alcancen a todos", con un 31,9\%; y "Conocimiento/desconocimiento de políticas públicas", con un 33,8\%. Se concluye que los adultos mayores elaboran significados que tienen como objetivo la necesidad de una mirada más implicada de la sociedad y de las instituciones para con el mayor, la humanización de lo vivido y el empoderamiento en la vejez.

Palabras clave: Adultos Mayores. Derechos humanos. Políticas públicas. Desigualdad psicosocial. Psicología socio-histórica.

\section{INTRODUÇÃO}

P elo contexto brasileiro de desigualdade que se vê no cotidiano, tem-se por objetivo neste estudo refletir sobre os significados dos direitos humanos e políticas públicas, a dimensão psicossocial, sob a ótica de idosos que vivem essa realidade. Trata de um subprojeto do projeto de pesquisa/intervenção intitulado Projeto de vida, trabalho e políticas públicas: emoção e consciência de jovens, adultos e idosos em contextos de exclusão, realizado pelo núcleo de estudos psicossociais de uma universidade pública, com apoio da Capes (Coordenação de Aperfeiçoamento de Pessoal de Nível Superior). O estudo é de caráter descritivo- 
analítico, realizado com idosos em atendimento em Serviço de Convivência e Fortalecimento de Vínculos para Idosos (SCFVI), referenciados pelo Centro de Referência e Assistência Social (CRAS) de uma cidade da Região Nordeste do País.

Desde a década de 1980, há diversas iniciativas internacionais que valorizam a possibilidade de se considerar a velhice como um processo positivo, pensado como um momento da vida de bem-estar e prazer. A política de desenvolvimento ativo, proposta pela (Organização Mundial da Saúde [OMS], 2005), é um exemplo real dessas recomendaçôes, enfatizando que envelhecer bem não é apenas responsabilidade do indivíduo e sim um processo que deve ser respaldado por políticas públicas e por iniciativas sociais e de saúde ao longo da vida. A princípio, a criação dessa política parte do pressuposto de que, para se viver a velhice de forma saudável, é fundamental aumentar a igualdade de oportunidades para que os indivíduos possam optar por um estilo de vida mais adequado, que inclui mudanças de hábitos alimentares e atividade física regular e, consequentemente, o controle da saúde física e psicológica. Assim, a definição da velhice ativa é apresentada como a "otimização das oportunidades de saúde, participação e segurança, com o objetivo de melhorar a qualidade de vida à medida que as pessoas ficam mais velhas" (OMS, 2005, p. 13).

A Política Nacional de Saúde da Pessoa Idosa (Brasil, 2006), e o Estatuto do Idoso (Lei no 10.741/2003) são dispositivos legais que norteiam ações sociais e de saúde, garantem os direitos das pessoas idosas e direcionam/exigem a ação do Estado na proteção destes. Porém é sabido que a efetivação de uma política pública requer atitude consciente e ética dos cidadãos envolvidos e interessados em envelhecer do modo mais saudável possível. Estado, profissionais da saúde, idoso e sociedade em geral são todos corresponsáveis por esse processo (Catão \& Grisi, 2014).

Tendo em vista as políticas e concepções postas, e os indicadores sociais do (Instituto Brasileiro de Geografia e Estatística [IBGE], 2010) sobre o crescente aumento da população idosa, no qual estimam que "o grupo de idosos de 60 anos ou mais de idade será maior que o grupo de crianças com até 14 anos de idade após 2030", bem como a crescente participação da população na luta pelos direitos sociais e construção de uma sociedade mais igualitária, desenvolveuse este projeto juntamente com o Serviço de Convivência e Fortalecimento de Vínculos para Idosos.

Diante do cenário político, social, cultural e econômico vigente, em que a desigualdade social, o desrespeito às diferenças, o afrontamento à dignidade humana, da cidadania passiva que se limita aos aspectos formais dos ritos 
democráticos, a cultura da injustiça e da falta de solidariedade têm provocado a redução do espaço de igualdade entre os grupos sociais (Hunt, 2009), justificamse produções e práticas que promovam a reflexão sobre esse cenário, buscando novas formas de superação do vivido.

Ao longo da vida, os seres humanos vivenciam um contínuo movimento de transição. Pela relação com os outros e consigo, aprendem, desenvolvem-se, são transformados e transformam a si, o outro e a história de vida (Vigotski, 1998; 2003; 2004; Vigotsky, 1977). Os estudos realizados por Vigotsky (1977; 1998; 2003) tratam do desenvolvimento humano contínuo ao longo da vida, configurado psicossocio-historicamente. Nessa perspectiva, o ser humano é visto em constante movimento, um ser inacabado e em contínuo processo. É importante destacar também que as capacidades que o sujeito vai adquirindo ao longo de seu desenvolvimento, pela relação com o meio, são o que vão conferirlhes as características tipicamente humanas, que a natureza, por si só, não garante (Vigotski, 1998; 2003; 2004). Nisso se justifica a dedicação a estudos como estes, em que se objetiva colocar o sujeito da situação em evidência, criando condiçôes que o faça perceber e desenvolver suas potencialidades.

O impacto psicológico que a velhice provoca nos seres humanos tem uma gênese psicossocio-histórica, fruto de resquícios de uma cultura que significam o idoso como alguém inútil, incapaz de novas realizações, não concebendo o idoso com possibilidade de desenvolvimento. A configuração psicossocio-histórica do desenvolvimento humano postula uma progressão contínua do desenvolvimento, desde o nascimento até a morte (Vigotski, 1998; 2004; Félix \& Catão, 2013).

Esta pesquisa foi realizada junto ao Serviço de Convivência e Fortalecimento de Vínculos para Pessoa Idosa (SCFVI) numa cidade da Região Nordeste do Brasil. O SCFVI constitui política de âmbito federal e faz parte das ações de assistência social desenvolvidas pela Prefeitura Municipal. Os grupos de idosos estão inseridos no nível de proteção básica, por meio dos Centros de Referência da Assistência Social (CRAS), são responsáveis pela efetivação dos direitos socioassistenciais e é o principal programa de proteção social básica do Sistema Único de Assistência Social (SUAS). O SCFVI, no que se refere ao atendimento à pessoa idosa, tem como objetivo o desenvolvimento de atividades que contribuam no processo de envelhecimento saudável, no desenvolvimento da autonomia e de sociabilidades, no fortalecimento dos vínculos familiares e do convívio comunitário e na prevenção de situações de risco social (João Pessoa, 2019).

Atualmente, a Prefeitura Municipal atende cerca de 2500 idosos, em 54 grupos de convivência distribuídos em quase todos os bairros da capital. Qualquer 
pessoa, a partir dos 60 anos, independentemente de condição socioeconômica ou gênero, pode participar do programa, recebendo acompanhamento psicológico e social, tirando dúvidas e sendo orientado sobre seus direitos.

\section{POLÍTICAS PÚBLICAS, DIREITOS HUMANOS, DESIGUALDADE: A DIMENSÃO PSICOSSOCIAL}

Como expressa Santos (2012), as políticas sociais são as políticas públicas que decorrem dos direitos econômicos e sociais dos trabalhadores e dos cidadãos em geral (população ativa efetiva, crianças, jovens, desempregados, idosos, reformados, "domésticas", produtores autônomos). Traduzem-se em despesas em bens e serviços consumidos pelos cidadãos gratuitamente ou a preços subsidiados: educação, saúde, serviços sociais, habitação, transportes urbanos, atividades culturais, atividades de tempos livres.

Em outras palavras, como traz Souza (2006), as políticas públicas compreendem o campo de conhecimento que busca "colocar o governo em ação". Elas podem ser entendidas como um conjunto de normas que orientam práticas e respaldam os direitos dos indivíduos em todos os níveis e setores da sociedade. Essas políticas devem ter como base os princípios da igualdade e da equidade, disseminando o sentido de justiça social, um conjunto de açôes coletivas que visam a garantir os direitos sociais e, no que se refere à pessoa idosa, assegurar que esta possa envelhecer com segurança e dignidade (Gomes, 2009). Por meio delas, os bens e serviços sociais são distribuídos, redistribuídos, de maneira a garantir o direito coletivo e atender às demandas da sociedade. Políticas públicas são diretrizes, princípios norteadores de ação do Poder Público; regras e procedimentos para as relaçôes entre Poder Público e sociedade, mediações entre atores da sociedade e do Estado. São, nesse caso, políticas explicitadas, sistematizadas ou formuladas em documentos (leis, programas, linhas de financiamentos) que orientam ações que normalmente envolvem aplicações de recursos públicos (Teixeira, 2002).

Refletir sobre as políticas públicas, os direitos humanos é analisar também o sujeito e sua subjetividade, não esquecendo sua construção no mundo. Assim como as células guardam as propriedades fundamentais do organismo vivo, o ser humano e sua subjetividade mantêm as características básicas dos problemas sociais (Vigotski, 2004; Vigotsky, 1977; Sawaia, 2006; 2010).

Analisar a dimensão psicossocial da desigualdade tem, no ser humano, sua unidade de objetivação. Isso significa colocar, no âmago das reflexões sobre os direitos humanos, a concepção de sujeito, de psicossocial e a ideia de humanidade como potência (Catão, 2015; Espinosa, 2009; Sawaia, 2006). Sem perder de vista 
o aspecto coletivo, deve-se dar força e relevância ao sujeito e sua configuração psicossocial, pois é nele que se referem as várias formas de necessidades e de direitos.

A subjetividade como dimensão psicossocial possibilita demonstrar a organização de um sistema dinâmico das funções psicológicas que se configuram continuamente, mediadas pelos significados e situações sociais, nos quais o afetivo e o intelectual, o corpo e a mente se unem (Vigotski, 2004). Dessa maneira, permite mostrar que cada ideia contém um sentido afetivo, revelador do subtexto das palavras, que é transmutado com relação ao fragmento de realidade ao qual se refere. Permite-nos, enfim, seguir a trajetória que vai das necessidades e impulsos de uma pessoa até a direção específica tomada por seus pensamentos e por sua atuação (Sawaia, 2006; 2010).

As políticas públicas e a Psicologia juntas vêm promovendo a possibilidade de contrapor à resistência ao processo de desenvolvimento que anula os direitos juntamente com os sujeitos de direitos; e o trabalho do psicólogo deve apontar para a transformação social, para a mudança das condições de vida da população brasileira. A Psicologia corrobora com a dinâmica das políticas públicas de forma que a intervenção dessa ciência é pensando como um trabalho mesmo que no nível individual, como uma intervenção social e, nesse sentido, posicionada (Gonçalves \& Bock, 2009).

No Brasil, a elaboração da Constituição de 1988, que foi distinta pelo alargamento do conceito de cidadania, favorece a evidência do papel e da ação política por parte do Estado. A Carta Magna se apresenta como um marco jurídico que estabelece propostas de garantia de direitos e proteção assim como fundamentos operacionais para o exercício da cidadania com possibilidade de avanço pela ação dos movimentos sociais e sociedade civil, aliados às proposiçôes de condução à efetivação de um panorama no qual as políticas públicas deverão contribuir com a elaboração de ações que amenizem os efeitos da desigualdade social e atendam a demandas específicas de populações pouco assistidas e socialmente vulneráveis.

Nesse direcionamento, a partir de 1994, os Conselhos de Defesa de Direitos das Pessoas Idosas foram oficializados no País, sendo compostos por representantes de órgãos governamentais e da sociedade civil. A regulamentação de conselhos municipais, estaduais, distrital e federal expressa a luta das pessoas idosas e dos movimentos sociais nesse campo e cria um espaço de participação política das pessoas, de exercício da cidadania, de possibilidade de maior intervenção do idoso na esfera pública, na reivindicação de direitos e de concretização de ações de seu interesse. 
Historicamente, podemos mencionar que a Política Nacional do Idoso, promulgada pela Lei no $8.842 / 1994$ e regulamentada pelo Decreto $\mathrm{n}^{\circ}$ 1.948/1996, também foi um marco para o reconhecimento desse segmento da sociedade. Tem como uma de suas diretrizes: "II - participação do idoso, através de suas organizações representativas, na formulação, implementação e avaliação das políticas, planos, programas e projetos a serem desenvolvidos" (art. $4^{\circ}$, Lei $\left.n^{\circ} 8.842 / 1994\right)$.

A base fundamental para o direito do idoso no Brasil é o Estatuto do Idoso, de iniciativa do Projeto de Lei no 3.561, de 1997, promulgado sob a Lei no 10.741 , de $1^{\circ}$ de outubro de 2003, sendo o seu foco destinado a regular os direitos assegurados às pessoas com idade igual ou superior a 60 anos. O Estatuto do Idoso coloca que são garantidos aos cidadãos idosos os direitos fundamentais inerentes à pessoa humana, que são a vida, a saúde, a alimentação, a educação, a cultura, o esporte, o lazer, o trabalho, a cidadania, a liberdade, a dignidade, o respeito e convivência familiar e comunitária.

A violência e os maus-tratos contra a pessoa idosa se expressam de forma física, psicológica, em violações de direitos como abandono, negligências, abuso financeiro e em comportamento de autonegligência. Constitui um problema universal que acomete todas as classes sociais, culturas, etnias e religióes, indicando que as estatísticas de violência contra a pessoa idosa são apenas "a ponta do iceberg de uma cultura relacional de dominação, de conflitos intergeracionais, de negligências familiares e institucionais" (Minayo, 2004, p. 26). Para Minayo (2004), esse panorama, presente na maioria das culturas, segrega os idosos, seja simbólica ou materialmente, e ainda deseja sua morte.

\section{MÉTODO}

Esta pesquisa foi realizada junto ao Serviço de Convivência e Fortalecimento de Vínculos para Pessoa Idosa (SCFVI), inserido no CRAS, principal programa do Sistema Único de Assistência Social (SUAS). Este estudo foi aprovado pelo Comitê de Ética, sob o parecer número 724 513/2014.

\subsection{Participantes}

Atualmente, a Prefeitura Municipal atende cerca de 2500 idosos, em 54 grupos de convivência distribuídos em quase todos os bairros da capital. Por conveniência do pesquisador, foi escolhido o serviço de convivência localizado nas proximidades da universidade geradora desta pesquisa. Nesse serviço de convivência o grupo é essencialmente feminino. Participaram do estudo 31 
mulheres, com idades entre 66 e 89 anos. Destas, 16,6\% tinham curso superior completo, $58,4 \%$ tinham o curso médio, e $25 \%$ cursaram entre a $1^{\text {a }}$ e a $4^{\mathrm{a}}$ série. Quando questionadas se estudam atualmente, 33,3\% responderam que faziam algum tipo de curso. Cinquenta por cento delas eram aposentadas e donas de casa, enquanto que as demais exerciam trabalhos informais. Com exceção de uma participante, moravam acompanhadas por alguém da família (seja o esposo, um filho, um neto, etc.), sendo que $25 \%$ tinham renda familiar entre 1 e 2 salários mínimos; $41,6 \%$, entre 2 e 4 salários; 8,3\%, entre 4 e 6 salários; e outros $25 \%$ tinham renda superior a 6 salários mínimos.

\subsection{Instrumentos e procedimento de coleta de dados}

Mediante a aceitação da coordenação do SCFVI bem como dos integrantes do grupo (pessoas idosas), deu-se início às atividades de campo, seguindo-se todos os procedimentos éticos de pesquisa para a realização do estudo. Foram aplicados dois questionários: um com objetivo de mapeamento psicossocial do SCFVI e outro de identificação das variáveis sociodemográficas dos membros do grupo de vivência, além de uma entrevista semiestruturada que abordou aspectos sobre "quando falo você, o que lhe vem?"; "o que você pensa/sente sobre isso?"; "quando falo direitos humanos, o que lhe vem?"; "quando falo direitos humanos e a pessoa idosa, o que lhe vem?"; "o que você pensa/sente sobre isso?"; "quando falo políticas sociais/políticas públicas, o que lhe vem?”; “o que você pensa/sente sobre isso?".

\subsection{Procedimentos de análise de dados}

$\mathrm{Na}$ interpretação e análise dos significados que emergiram nas falas dos participantes, foi utilizado o método de análise de conteúdo temática (Bardin, 1978). O plano de análise aplicado desenvolveu-se da seguinte forma: organização do corpus constituído pelas 31 entrevistas realizadas com as pessoas idosas; leitura em profundidade, identificação dos eixos temáticos e interpretação referencial. Denominaram-se os sentidos à luz do referencial teórico-conceitual do estudo. Procurou-se, assim, dar atenção ao conteúdo manifesto e aprofundar a análise para desvendar o conteúdo latente expresso nas falas dos participantes da pesquisa. 


\section{RESULTADOS E DISCUSSÃO}

Este estudo pôde dar ênfase não somente à construção dos significados de direitos humanos e políticas públicas como também proporcionou aos participantes um momento de reflexão sobre tal construção. Observou-se essa reflexão visto que a construção do significado se entrelaçava ao mundo vivido daqueles indivíduos.

Os significados sobre direitos humanos e políticas públicas elaborados por idosos em serviço de convivência, com base no material coletado pelas entrevistas, foram capturados em três eixos temáticos: a responsabilidade é do governo e dos representantes, com 34,3\% das falas; ausência de direitos que alcancem a todos, com 31,9\%; conhecimento/desconhecimento de políticas públicas, com 33,8\%, como pode ser observado na tabela 1 .

\section{Tabela 1- Distribuição de eixos temáticos sobre significados dos direitos humanos e políticas} públicas por idosos em serviços de convivência

\begin{tabular}{|c|c|c|}
\hline Eixos temáticos & (f) & $\%$ \\
\hline $\begin{array}{l}\text { A responsabilidade } \\
\text { é do governo e dos } \\
\text { representantes }\end{array}$ & 58 & 34,3 \\
\hline $\begin{array}{l}\text { Ausência de direitos que } \\
\text { alcancem a todos }\end{array}$ & 54 & 31,9 \\
\hline $\begin{array}{l}\text { Conhecimento/ } \\
\text { desconhecimento de } \\
\text { políticas públicas }\end{array}$ & 57 & 33,8 \\
\hline Total & 169 & 100 \\
\hline
\end{tabular}

\subsection{Direitos humanos e políticas públicas: significados}

Os idosos apresentaram visões diferenciadas. Por um lado, elaboraram concepções sobre direitos humanos e políticas públicas configurados como ação e responsabilidade do governo e de seus representantes, apresentando-se como uma perspectiva crítica, mas, ao mesmo tempo, de passividade no processo de busca por direitos, responsabilizando única e exclusivamente os representantes de governo: "Pra mudar mesmo alguma coisa, depende muito dos políticos, né. Se eles cumprissem mais o que falam [. . .]" (76 anos); "Acho que o governo não investe em direitos humanos e políticas" (65 anos).

Outra parte se diz aproveitar bem das políticas públicas existentes e que estas estão postas de modo satisfatório: "Hoje eu tô aprendendo a ler pelo Programa Brasil Alfabetizado" (66 anos); "Não tenho plano de saúde, mas nunca fiquei 
sem atendimento também, o SUS dá conta. Por enquanto, acho que tá tudo bem" (79 anos).

Outros afirmam não existirem direitos humanos, pelo menos não para todos: "A gente vai procurar os direitos da gente, e não encontra. E, pra encontrar, é muita dificuldade, muito trabalho" (67 anos); "Eu não vejo prática dos direitos humanos, não; sinceramente, não vejo importância disso. Eles dão mais direito aos errados do que aos certos" (69 anos).

Foi possível verificar um distanciamento dos idosos na busca por seus direitos. Observou-se que o desconhecimento ainda era mais comum do que se imaginava. Polignano (2003) expressa que houve um tempo em que pouco ou nada se falava dos direitos sociais e, apesar de esse comportamento vir modificandose nas últimas décadas, percebe-se que, especificamente entre as pessoas idosas, ainda há pouca informação acerca disso, o que acaba gerando uma falta de protagonismo na luta por seu lugar social. Contudo vale destacar que o acesso ao serviço de fortalecimento de vínculos por meio dos grupos de convivência tem sido um agente de mudança nesse sentido, minimizando os efeitos da exclusão historicamente sofrida.

As narrativas apontaram ações que deveriam ser feitas nas mais diversas áreas, como educação e segurança: "Olha, educação precisava ser uma coisa mais organizada, mais estudada. A gente tem os neto da gente que estuda, a gente vê dificuldade de um lado, dificuldade do outro e tá faltando, assim, um pouco de ajuda do nosso governo" (79 anos); "Também outra coisa que eu estou achando assim muito ruim na minha vida é a violência. Eu até saía de noite, adorava ir para o teatro; hoje eu não vou mais pra canto nenhum, porque a violência tipo que tá, não tem história de ser novo ou velho mais, né?" (69 anos); "Isso aí tá ficando uma coisa que a gente tá cada dia ficando com mais medo, vai chegar um ponto de ficar gente... muitas pessoas com... com síndrome do pânico de sair de casa” (69 anos). Observa-se, nas falas postas, a vontade, por parte da entrevistada, de ser independente e sair sozinha, entretanto a ausência de companhia e a situação de insegurança contribuem para a vulnerabilidade do idoso.

Indagou-se a uma entrevistada de quem depende essas açóes, e ela expressou: "Ué, depende das autoridades! Depende do governo federal, governo estadual, prefeitos, políticos, vai. Políticos no geral, aqui está faltando isso" (79 anos). Verifica-se que todas as falas apontam como principal responsável o governo pela concretização dessas açôes: "Acho que o governo, né? Sim. Prefeito, governo, tudinho... Deveria ajudar" (65 anos). Pensa-se que a consciência refletida da população no sentido de cobrar das autoridades maior compromisso é fundamental para mudar esse panorama. 
Os relatos dos sujeitos, no que dizem respeito à temática, retratam a forma com que veem a ação e a não ação no sentido do acesso aos direitos humanos e políticas públicas, bem como o entendimento que têm sobre a temática. "Direitos humanos é um direito que a gente tem, é ser tratado com respeito, ser cuidado com mais atenção, direitos humanos é olhar pra gente, cuidar das pessoas" (72 anos); "Os direitos humanos poderiam ser melhores em relação a mais humanização, em relação à violência, que olhassem um jeito de mudar a situação" (68 anos); "Direitos humanos, pra mim, é o direito da pessoa, eu entendo que são os direitos dos cidadãos, das pessoas, só isso mesmo. Políticas públicas e sociais eu não sei o que falar não. Não entendo muito" (58 anos); "Em relação aos direitos humanos e política social/política pública, eu não sei responder não" (73 anos).

Como foi possível observar, a temática dos direitos humanos é mais destacada pelos sujeitos participantes, apesar de ainda tímida, do que a política pública. Nesse aspecto existiu um certo distanciamento no que se referia ao entendimento dos participantes sobre a temática da política pública, apesar de estarem sendo beneficiados e frequentarem um serviço público de assistência à pessoa idosa. Esse distanciamento reforça a necessidade do trabalho de conscientização desses sujeitos, no sentido de incentivá-los a entender mais sobre o tema e posteriormente estarem inseridos nos debates, na luta pela melhoria dos serviços e na cobrança pelos seus direitos. Além disso, o trabalho com esses sujeitos proporciona uma reflexão sobre a implicação destes, qual o seu papel na sociedade.

No âmbito das políticas públicas, são consideradas também as "não ações", as omissões, como formas de manifestação de políticas, pois representam opções e orientaçôes dos que ocupam cargos.

Como o poder é uma relação social que envolve vários atores com projetos e interesses diferenciados e até contraditórios, há necessidade de mediaçōes sociais e institucionais, para que se possa obter um mínimo de consenso e, assim, as políticas públicas possam ser legitimadas e obter eficácia (Teixeira, 2002, p. 2).

Nesse sentido, os sujeitos relataram os seus sentimentos de descontentamento em relação aos serviços prestados à sociedade, especificamente à população idosa: "Em relação ao acesso, em fase de aposentadoria e envelhecimento, a saúde é péssima, o atendimento demora, a gente faz um exame, o resultado demora muito" (70 anos); "Em geral, tem que melhorar muito" (70 anos); "O acesso aos serviços poderia melhorar, todos os setores, segurança, moradia, a saúde e a educação. As coisas estão mudando um pouco, não mudou muito não, mas vem caminhando, tá melhorando" (72 anos); "Os idosos são humilhados nos serviços em geral" (63 anos). 
Da mesma forma que se negam açôes, como citado anteriormente, ao se negar o sofrimento também se nega a cidadania, portanto é fundamental focalizar-se na exclusão pelas emoções dos que a vivenciam. É preciso capturar a afetividade, o sofrimento ético político (Sawaia, 2006) quando se reflete sobre os excluídos, deve-se ressaltar a questão do sofrimento presente nas injustiças sociais, na opressão, na exploração e o não reconhecimento de seus direitos (Lima, Bomfim, \& Pascual, 2009).

\section{CONSIDERAÇŌES FINAIS}

Como bem destaca Höfling (2001), as políticas sociais se referem a ações que determinam o padrão de proteção social implantado pelo Estado, voltadas, em princípio, para a redistribuição dos benefícios sociais visando à diminuição das desigualdades estruturais produzidas pelo desenvolvimento socioeconômico. Este estudo possibilitou inicialmente aos pesquisadores uma visão geral do perfil do ser idoso e os significados dos direitos humanos e políticas públicas elaborados por eles, sob o enfoque da perspectiva sócio-histórica, considerando o sujeito em constante movimento de relação eu e o outro, num processo dialético da intersubjetividade e objetividade, criador e criatura (Vigotski, 2003; 2004).

Os resultados apontam para um nível de descontentamento dos participantes em relação ao tratamento da sociedade e das instituições para com o idoso. Observa-se também um distanciamento no que se refere à tomada de consciência de seus direitos e do próprio conceito de direitos humanos e políticas públicas. Conclui-se que é necessário um maior empoderamento dos sujeitos quanto ao conhecimento, questionamento, reflexão e acesso aos direitos humanos e políticas públicas, humanizando o vivido na velhice. 


\section{REFERÊNCIAS}

Bardin, L. (1978). Análise de conteúdo. Lisboa: Edições 70.

Brasil. Ministério da Saúde. (2006). Envelhecimento e saúde da pessoa idosa. Brasília: Ministério da Saúde.

Catão, M. F. (2015). Psicologia Sócio-Histórica e pesquisa/intervenção: constituição do sujeito e transformação social. In S. T. F Martins (Org.), Psicologia Sócio-Histórica e pesquisalintervenção: constituição do sujeito e transformação social. (pp. 143-155). Goiânia: Ed. PUC Goiás.

Catão, M. F. \& Grisi, A. F. M. (2014). Life project and work as matter of exclusion/inclusion of the elderly person. Estudos em Psicologia, 31(2), 215-223. Recuperado a partir de https://dx.doi.org/10.1590/0103166X2014000200007

Espinosa, B. (2009). Ética. Belo Horizonte: Autêntica.

Felix, Y. T. M., \& Catão, M. F. (2013). Envelhecimento e aposentadoria por policias rodoviários. Psicologia \& Sociedade, 25(2), 420-429. Recuperado a partir de http://www.scielo.br/scielo.php?script=sci_arttext\&pid=S010271822013000200019\&lng=en\&tlng=pt

Gomes, S. (2009). Políticas públicas para a pessoa idosa: marcos legais e regulatórios. São Paulo: Fundação Padre Anchieta.

Gonçalves, M. G. M. \& Bock, A. M. B. (2009). A dimensão subjetiva dos fenômenos sociais. In M. G. M. Gonçalves \& A. M. B. Bock (Org.), A dimensão subjetiva da realidade: uma leitura sócio-histórica. (pp. 116-157). São Paulo: Cortez.

Höfling, E. D. M. (2001). Estado e políticas (públicas) sociais. Cadernos Cedes, 21(55), 30-41.

Hunt, L. (2009). A invenção dos direitos humanos: uma história. São Paulo: Companhia das Letras

Instituto Brasileiro de Geografia e Estatística. (2010). Perfil dos municípios brasileiros: assistência social 2009. Rio de Janeiro: IBGE.

João Pessoa. Prefeitura Municipal. (2019). Serviço de Convivência e Fortalecimento de Vinculos. João Pessoa: Prefeitura Municipal. Recuperado a partir de 
http://www.joaopessoa.pb.gov.br/secretarias/sedes/servico-de-convivencia-efortalecimento-de-vinculos

Lei no 8.842, de 4 de janeiro de 1994. (1994, 4 janeiro). Dispõe sobre a política nacional do idoso, cria o Conselho Nacional do Idoso e dá outras providências. Diário Oficial da Uniāo, Brasília. Recuperado a partir de http://www.planalto. gov.br/ccivil_03/leis/18842.htm

Lei $\mathrm{n}^{\circ} 10.741$, de $1^{\circ}$ de outubro de 2003. (2003, $1^{\circ}$ outubro). Dispóe sobre o Estatuto do Idoso e dá outras providências. Diário Oficial da União, Brasília. Recuperado a partir de http://www.planalto.gov.br/ccivil_03/leis/2003/ 110.741.htm

Lima, D. M. A., Bomfim, Z. A. C., \& Pascual, J. G. (2009). Emoção nas veredas da Psicologia Social: reminiscências na filosofia e psicologia histórico-cultural. Psicologia Argumento, 27(58), 231-240.

Minayo, M. C. S. (2004). Violência contra idosos: o avesso do respeito à experiência e à sabedoria. Brasília: Secretaria Especial dos Direitos Humanos.

Organização Mundial da Saúde. (2005). Envelhecimento ativo: uma politica de saúde. Brasília: Organização Pan-Americana da Saúde.

Polignano, M. V. (2003). História das políticas públicas no Brasil: uma pequena revisão. Mato Grosso: Governo do Estado de Mato Grosso.

Santos, B. S. (2012). O Estado social, Estado providência e de bem-estar. Diário de notícia, 29 dezembro, 2012. Recuperado a partir de https://www.dn.pt/ opiniao/opiniao-dn/convidados/interior/o-estado-social-estado-providenciae-de-bem-estar-2968300.html

Sawaia, B. B. (2006). O sofrimento ético-político como categoria de analise da dialética exclusão/inclusão. In B. B. Sawaia (Org.), As artimanhas da exclusão: uma análise ético-psicossocial da desigualdade. (pp. 97-119). Petrópolis: Vozes.

Sawaia, B. B. (2010). Psicologia e desigualdade social: uma reflexão sobre liberdade e transformação social. Psicologia \& Sociedade, 21(3), 364-370. Recuperado a partir de http://dx.doi.org/10.1590/S0102-71822009000300010

Souza, C. (2006, julho-dezembro). Políticas públicas: uma revisão de literatura. Sociologias, 8(16), 20-45. Recuperado a partir de http://www.scielo.br/pdf/ soc/n16/a03n 16 
Teixeira E. C. (2012). O papel das politicas públicas no desenvolvimento local e na transformação da realidade. Salvador: AATR.

Vigotski, L. S. (1998). Psicologia da arte. São Paulo: Martins Fontes.

Vigotski, L. S. (2003). Pensamento \& linguagem. São Paulo: Martins Fontes.

Vigotski, L. S. (2004). Teoria e método em Psicologia. São Paulo: Martins Fontes.

Vigotsky, L. S. (1977). Las emociones y su desarrollo en la edad infantil. Madrid: Visor.

Vigotsky, L. S. (1997). Sobre los sistemas psicológicos. Madrid: Visor. 